\title{
Toponímia na escola: um olhar interdisciplinar sobre o bairro
}

\author{
Giselle Olivia Mantovani Dal Corno*
}

Elisa Jaques dos Santos ${ }^{* *}$

\begin{abstract}
Resumo: O presente trabalho tece algumas considerações sobre como os estudos em toponímia podem contribuir para a promoção da cidadania e o sentimento de pertinência dos indivíduos à sua comunidade. Partimos de uma investigação sobre o conhecimento de aspectos da toponímia do bairro Nossa Senhora de Lourdes, no município de Caxias do Sul, RS. Com a aplicação de um questionário nas $5^{\text {a }}$ séries do Ensino Fundamental de uma escola localizada no bairro pesquisado, levantamos dados para verificar se o conhecimento dos nomes dos lugares constitui uma prática educativa de fato significativa para os educandos. Em seguida, elaboramos uma proposta de atividades, envolvendo as disciplinas de Língua Portuguesa, História, Geografia e Educação Artística, de modo a contribuir para uma melhor compreensão do bairro e da cultura local.
\end{abstract}

Palavras-chave: Ensino Fundamental, Toponímia, Interdisciplinaridade, Caxias do Sul, RCI.

Abstract: This paper reflects on how studies in toponomy may contribute for the promotion of citizenship and the individuals' feeling of belonging to their community. The starting point was investigating how much 5 th graders of a school in the city of

\footnotetext{
Doutora em Letras - Estudos da Linguagem. Docente e pesquisadora do Programa de Pós-Graduação em Letras, Cultura e Regionalidade da Universidade de Caxias do Sul. E-Mail: mandal@terra.com.br

** Acadêmica do Curso de Letras da Universidade de Caxias do Sul e bolsista de Iniciação Científica CNPq. E-mail: elisajs@hotmail.com.
} 
Caxias do Sul, RS, Brazil know about the toponomic aspects of the neighborhood in which the school is located, called Nossa Senhora de (Our Lady of) Lourdes. The next step was the development of a set of activities involving Language, History, Geography and Arts, in order to get students to learn more about their neighborhood and the culture they live in.

Keywords: Elementary school, Toponomy, Interdisciplinary teaching, Caxias do Sul, RCI.

\begin{abstract}
As estradas e praças nascem com os povoados, como elementos integrantes do contexto social, facilitadores da vida do grupo humano. No espaço público que ocupam, os homens abrem caminhos, trocam saberes, constroem sua história. Um signo toponímico não é um mero sinal gasto pela passagem do tempo ou pela sucessão de múltiplas gerações: ele é uma síntese poderosa, um elo importante na corrente do tempo pondo em correlação fatos, acontecimentos e açóes dos homens. (FROSI, 2009, p. 3025)
\end{abstract}

É sabido que a constituição física do espaço - urbano ou não - é estudada centralmente pela Geografia, assim como sua evolução, especialmente se relacionada à sua ocupação humana, é objeto de estudo da História. Geografia e História são duas disciplinas constantes nos currículos escolares desde os anos iniciais, e como tal, dados geográficos e fatos históricos são estudados com apoio de vasta oferta de material didático. No entanto, que disciplina se ocupa na escola de investigar os nomes que os lugares recebem e como se deu essa nomeação? Que disciplina se preocupa em associar as denominações de lugares aos dados histórico-geográficos que lhes serviram de motivação, ou mesmo de explicar a formação linguística desses nomes? A intricada rede de elementos por trás dos procedimentos denominativos de lugares é objeto de estudo da Toponímia, uma área interdisciplinar que se localiza no grande campo dos Estudos Lexicais. Servindo-se do conhecimento oriundo da História, da Geografia, dos estudos culturais, linguísticos e até dialetológicos, para citar 
alguns, a Toponímia ocupa-se de um recorte específico do léxico de uma língua, a saber, os nomes próprios dados a lugares, os chamados "topônimos".

A nomeação dos espaços é uma "atividade humana inerente ao homem", como diz Carvalhinhos (2008, não paginado). O ato da denominação de lugares é, por conseguinte, como qualquer outra atividade humana, passível de investigação científica e sistematização. Uma evidência disso é a taxonomia de topônimos sistematizada para a língua portuguesa por Dick (1996), uma das pioneiras nos estudos toponímicos no Brasil. Esse tipo de investigação não serve apenas para satisfazer a curiosidade do pesquisador; mais importante, é uma forma de estabelecer, através do estudo desse recorte do léxico, as relações entre os lugares e os indivíduos que por ali passa(ra)m ou que o habita(ra)m, pois o léxico

[...] representa a janela através da qual uma comunidade pode ver o mundo, uma vez que esse nível da língua é o que mais deixa transparecer os valores, as crenças, os hábitos e costumes de uma comunidade, como também, as inovações tecnológicas, transformações sócio-econômicas e políticas ocorridas em uma sociedade.” (OLIVEIRA; ISQUERDO, 2001, p. 9)

A interdisciplinaridade inerente aos estudos toponímicos vem ao encontro do que preconizam os Parâmetros Curriculares Nacionais. Eles apontam que um dos objetivos do ensino fundamental é "Conhecer características fundamentais do Brasil nas dimensões sociais, materiais e culturais como meio para construir progressivamente a noção de identidade nacional e pessoal e o sentimento de pertinência ao país." (PCNs, 1998, p. 07). Sob essa perspectiva, a inclusão de estudos direcionados à Toponímia na escola contribui para um maior entendimento da cultura local.

Por acreditarmos que o estudo dos topônimos reveste-se de particular significado para a compreensão das comunidades (e, por extensão, dos povos), conduzimos uma investigação em uma escola do bairro Nossa Senhora de Lourdes, em Caxias do Sul, RS, cujo objetivo foi o de verificar o conhecimento toponímico 
adquirido por alunos da $5^{\text {a }}$ série com relação ao bairro. $\mathrm{O}$ estudo originou-se do projeto de pesquisa "Os nomes da cidade de Caxias do Sul: vias, bairros, praças, monumentos - TOPONÍMIA", coordenado pela professora Vitalina Maria Frosi e desenvolvido na Universidade de Caxias do Sul entre 2007 e 2010; teve como propósito principal realizar um estudo dos topônimos da cidade, a fim de contribuir para a construção e preservação da identidade cultural da Região de Colonização Italiana do nordeste do Rio Grande do Sul (RCI).

Dentro dessa perspectiva, apresentamos uma proposta, a partir dos dados obtidos, buscando oferecer à escola algumas alternativas para o estudo dos topônimos como motivação eficaz para o trabalho interdisciplinar. Focalizamos aqui os aspectos toponímicos dentro do âmbito de uma cidade; assim, o trabalho é realizado do ponto de vista da microtoponímia, lidando mais especificamente com os hodônimos (isto é, os topônimos que denominam ruas, praças, monumentos etc.). Pretendemos com este trabalho refletir sobre a importância de práticas educativas que promovam o estudo dos topônimos como forma de envolvimento entre escola, família e administração municipal, bem como de desenvolvimento da cidadania dos educandos.

Para melhor compreensão do objeto de estudo, apresentamos, inicialmente, uma breve caracterização do bairro, seguida do relato da investigação conduzida e da descrição da proposta apresentada.

\section{Caracterização do bairro Nossa Senhora de Lourdes}

Os nomes estão intimamente relacionados com a trajetória de vida dos homens que fundam e habitam os lugares, com a história e o desenvolvimento socioeconômico desses lugares, com a origem etnolinguística dos indivíduos e, no contexto de Caxias do Sul, com a cultura originária transplantada no país acolhedor. Nessa malha de relações, incluem-se, 
certamente, também segmentos importantes do universo cultural do país brasileiro. (FROSI, 2010, p. 54).

Caxias do Sul é uma cidade localizada na encosta superior do nordeste do Rio Grande do Sul, que tem como uma de suas principais características o fato de ter sido uma das sedes a receber as famílias de imigrantes chegadas da Itália, a partir de 1875. Eram as chamadas colônias, que se constituíram sobre as terras devolutas no sul do Brasil para atender à necessidade colocada pelo Governo Imperial de ocupação e povoamento. A Colônia Caxias logo em 1890 transformou-se em município e, em 1910, foi elevada à categoria de cidade. Nacionalmente conhecida pela Festa da Uva, Caxias conta hoje com 65 bairros e é dividida em nove regiões administrativas e oito distritos, tendo sido contabilizados, no último Censo de 2010, pouco mais de 430 mil habitantes.

Dados históricos sobre Caxias do Sul, localizados em publicações diversas e complementados com os disponibilizados em entrevistas do Banco de Memória do Arquivo Histórico Municipal João Spadari Adami, indicam que o bairro Nossa Senhora de Lourdes foi o segundo bairro criado em Caxias do Sul, em direção leste a partir do Centro, iniciando na segunda rua após a praça central (atualmente denominada Borges de Medeiros) e terminando na Estrada Conselheiro Dantas. Essa estrada, inaugurada em 1883, era a saída para os Campos de Cima da Serra, e por ela chegavam os tropeiros para se abastecer nos armazéns do bairro, como, por exemplo, o de Vicente Rovea. ${ }^{1}$

O bairro teve como denominação inicial "Caipora", nome que vem do tupi ka'apora, formado de $k a$ 'a, "mato" e pora "habitante de". Além da ideia de "habitante do mato", também comportava o significado de "pessoa infeliz, coitado", motivo pelo qual muitas pessoas ficavam constrangidas em dizer que

\footnotetext{
O prédio do armazém de Vicente Rovea serviu depois como o Hospital Carbone e, após movimentos de protesto contra sua demolição, foi adquirido em 1985 pela Prefeitura e hoje é ocupado pelo Arquivo Histórico Municipal João Spadari Adami. (GIRON; BERGAMASCHI, 2001).
} 
moravam ali, de acordo com depoimentos disponíveis no Banco de Memória. Provavelmente por este motivo, houve a sugestão para substituição desse nome. O Acto 48 da Administração Municipal de Caxias do Sul, de 5 de agosto de 1930, justificava que o bairro merecia "denominação mais adequada", e através dele o bairro passou a se chamar "Guarani" (ou "Guarany", em alguns registros). Essa segunda denominação contrasta radicalmente com a primeira, pois alude às características de bravura e coragem do povo homônimo e falante da língua também homônima, antigo habitante, predominantemente, das regióes compreendidas entre Paraguai, Argentina e sul do Brasil. A figura heróica e nobre do índio guarani foi exaltada e mitificada através do romance de José de Alencar. Ainda hoje está em plena atividade o Clube Guarany, em cuja entrada encontra-se uma imponente figura de um índio empunhando um arco e flecha, muito embora o clube já não se encontre dentro dos limites atuais do bairro após a nova delimitação, datada da segunda metade do século XX.

Já no final do século XIX havia sido construída no bairro uma capela, a do Santo Sepulcro, reiterando a religiosidade do imigrante italiano. A capelinha de madeira foi substituída por uma edificação em alvenaria, inaugurada em 1937, sendo hoje um importante ponto turístico por seus vitrais, pelas esculturas em madeira e pelo afresco do pintor italiano Aldo Locatelli (dados que a levaram recentemente a ser declarada Patrimônio Histórico Municipal). Poucos anos depois, deu-se início à construção, num ponto do bairro mais distante do Centro, de outra pequena igreja de madeira em terreno doado por Luiz Michielon, ao lado da cantina da família. No lugar dela, foi posteriormente erigida uma grande igreja, inaugurada em 1942, homenageando Nossa Senhora de Lourdes, cujas aparições teriam se dado na França, em 1858. Em função dessa nova igreja, o bairro foi rebatizado, sendo também, neste mesmo ano, seus limites modificados. A capela do Santo Sepulcro, com essa modificação, se encontra hoje fora dos limites do bairro, mas continua sendo ligada à paróquia de Lourdes. Observa-se, nessa segunda alteração do nome do 
bairro, a prevalência do espírito religioso da comunidade, uma tendência, aliás, bastante forte em Caxias, uma vez que há pelo menos dez outros bairros fazendo referência a santos ou figuras sagradas da religião católica.

Não associamos essa alteração de denominação à tendência que se verificava fortemente na RCI e na cidade de substituição de nomes alusivos à cultura italiana por outros exaltando o espírito nacional brasileiro. Pelo contrário, tem-se aqui a substituição de um nome brasileiro, representando uma nação indígena, por o de uma divindade, quando a prática mais comum na época era exatamente o inverso (haja vista a mudança do nome da praça central de Caxias do Sul, Dante Alighieri, para Rui Barbosa, exatamente em 1942. ${ }^{2}$

O bairro comporta ainda outros importantes símbolos de Caxias do Sul, como o Monumento ao Imigrante - a última obra do arquiteto italiano Silvio Toigo, radicado em Caxias (COSTA; MACHADO; VENZO, 2008) - e o próprio prédio do Arquivo Histórico Municipal. Conta com um parque (Parque da Imprensa) e praças (Praça Abramo Eberle, homenagem a um dos pioneiros da indústria metalúrgica na cidade; Praça Vestibular Presidente Getúlio Vargas, homenagem feita ao presidente quando de sua visita à cidade). Conserva outras edificações representativas de períodos da história da cidade, como construções em estilo art-dèco, prédios comerciais e casario antigo; a escadaria que liga a Avenida Júlio de Castilhos à parte mais alta do bairro (necessária em função do rebaixamento do leito da avenida para melhor acesso bairro-centro), além da própria escola em que foi aplicada a pesquisa. Sua ampla edificação atual está localizada onde havia, no início do século XX, o orfanato Santa Teresinha, fundado e administrado por Angelina Michielon, descendente de imigrantes italianos, que dá nome a uma das ruas que ladeiam a escola. Essa rua, por sinal, é uma das cinco cujo nome homenageia uma figura feminina, do total das 56 ruas do bairro. Dessas, outras 45 homenageiam figuras masculinas. Temos, assim, 50

A esse respeito, ver Frosi, Faggion e Dal Corno (2008). 
antropo-hopônimos (isto é, hodônimos constituídos por nomes de pessoas) num universo de 56 hodônimos. ${ }^{3}$ Considerando que a grande maioria das figuras homenageadas é constituída por habitantes da cidade, isso revela a importância atribuída pelas instâncias administravas municipais àqueles que contribuíram para a construção da cidade.

\section{A investigação conduzida}

Tradicionalmente, a cidade e o bairro são tópicos de ensino no terceiro ou quarto anos do Ensino Fundamental (correspondentes, respectivamente, à $2^{\mathrm{a}}$ e à $3^{\mathrm{a}}$ séries do Ensino Fundamental da modalidade com 8 anos de duração). O objetivo da abordagem a esses tópicos parece claro: dar à criança o conhecimento sobre o local onde vive, a fim de contribuir para sua inclusão como cidadã nesse local. Ao propor essa investigação, nosso interesse era o de verificar em que medida as informações apresentadas sobre o bairro haviam sido assimiladas, de modo a revelar o significado atribuído a esse conhecimento pelo próprio aluno. Cabe ressaltar que, na condução da investigação e na proposta posteriormente elaborada, não houve qualquer intenção de avaliar ou julgar o trabalho realizado na escola. Pelo contrário, nosso objetivo com este trabalho é o de reforçar a importância dos estudos toponímicos juntamente com os demais componentes curriculares e propor estratégias para sua promoção de forma lúdica e eficaz.

A pesquisa foi conduzida na principal escola particular do bairro Nossa Senhora de Lourdes, no município de Caxias do Sul. Trata-se de uma escola tradicional da cidade, tendo sido fundada em 1928 por uma congregação religiosa que veio à cidade a convite das famílias do bairro. Atualmente atende a cerca de 1.350 alunos, entre Ensino Fundamental e Médio e, desde o ano letivo de 2006, passou a oferecer o Ensino Fundamental

Agradecemos à Profa. Vitalina M. Frosi pelo precioso auxílio na classificação dos hodônimos. 
com nove anos, motivo pelo qual hoje se encontram algumas turmas remanescentes do curso no formato anterior, organizado em oito séries.

Os dados foram coletados através de questionários estruturados, aplicados pela própria equipe da escola a quatro turmas de $5^{\text {a }}$ série, totalizando 107 alunos, identificados apenas pelo número da turma. Como, no entanto, interessava-nos observar o conhecimento formal adquirido a respeito do bairro em que a escola se situa, descartamos os questionários respondidos por alunos que não cursaram na escola a segunda ou terceira séries, quando teriam estudado esse tópico, o que nos deixou com 89 questionários para análise.

As questões a que os alunos responderam foram:

1. Qual é o nome completo do bairro em que se localiza o colégio?

2. Sabe por que o bairro tem esse nome hoje?

3. Este bairro já teve dois outros nomes. Sabe quais são?

4. O colégio fica na rua Angelina Michielon. O que você sabe sobre a mulher que esse nome homenageia?

5. Se viesse um turista para conhecer o bairro, o que você mostraria e ele?

Esperávamos obter como respostas corretas:

- "Nossa Senhora de Lourdes", para a primeira questão; alguma relação com a religiosidade dos imigrantes ou, no mínimo, referência à igreja do mesmo nome, para a segunda questão;

- "Caipora" e "Guarani”, para a terceira questão; alguma referência ao orfanato mantido por Angelina Michielon, para a quarta questão;

- Pelo menos os pontos turísticos mais conhecidos, como o Monumento ao Imigrante, a Capela do Santo Sepulcro e o Arquivo Histórico Municipal, para a quinta questão. 
- As respostas dadas pelos alunos foram bem menos satisfatórias do que esperávamos, como se pode observar pelos números percentuais descritos abaixo: apenas 22 informantes $(24,7 \%)$ sabiam o nome completo do bairro;

- O motivo para a denominação atual do bairro foi respondido corretamente por somente dois alunos $(2,4 \%)$;

- Os nomes anteriores do bairro não foram citados pelos estudantes $(0 \%)$;

- Sobre o nome da mulher que a rua da escola homenageia, apenas um aluno $(1,2 \%)$ respondeu corretamente;

- Em relação aos pontos turísticos, foram citados: a Igreja Nossa Senhora de Lourdes por 32 alunos $(35,9 \%)$; o Monumento ao Imigrante, por apenas 7 alunos $(7,8 \%)$. A menção à Escola, feita por 33 alunos (37\%), aponta para a importância da instituição na vida das crianças.

Os resultados podem indicar que, mesmo que o bairro tenha sido um tema bem abordado na segunda ou terceira séries, houve pouca assimilação das informações por parte dos educandos, o que pode ter se dado por uma infinidade de motivos diferentes. Independentemente dos motivos, pode-se constatar que não houve uma apropriação (pelo menos não duradoura) desse conhecimento por parte do aluno.

$\mathrm{O}$ que se perde com isso?

Em primeiro lugar, parte do passado da cidade. Muito da história cultural do município pode ser associada às modificações por que passou a denominação do bairro. Sem conhecer as primeiras ruas do bairro e saber os estabelecimentos comerciais que existiram é mais difícil compreender a inclusão de Caxias do Sul no movimento de urbanização da região do final do século XIX, sendo um ponto de parada obrigatório dos tropeiros, ou a história da formação da cidade e do bairro, ou mesmo a associação da história da imigração com seus valores culturais e religiosos. 
O conhecimento de hodônimos, como nomes de praças e de ruas, pode indicar que elementos e pessoas eram valorizados e sugerir motivos para tal. A história do Monumento ao Imigrante, por exemplo, se reveste de peculiar significado. Após quase uma década de propagação dos ideais de nacionalismo do Governo Federal, com consequências negativas para toda a população de descendência estrangeira - em Caxias do Sul, essencialmente italiana -, a inauguração do monumento significou uma tentativa de fazer um reconhecimento público (talvez em retratação) à contribuição dos imigrantes para a formação da cidade e de toda a RCI. Um monumento faz uma homenagem, mas também conta uma história.

Quantos alunos terão se perguntado por que há uma escadaria no bairro? Quantos terão realmente percebido a existência dela? Há questões de topografia a discutir, questões de urbanização, que explicariam a necessidade de a rua ter sido rebaixada, de haver uma ligação entre as partes em desnível. Uma prova dessa mudança de nível está na fachada do prédio do Arquivo Histórico, que tem à mostra o andar térreo de estrutura um pouco diferente do restante, porque, inicialmente, esse andar era subterrâneo.

Quais são os diferentes estilos arquitetônicos identificados no casario antigo, nos prédios de estabelecimentos comerciais? Que importantes exemplos concretos estão à disposição dos alunos que circulam pelas calçadas do bairro!

Não menos importante, o trabalho com os topônimos pode ainda propiciar o resgate de histórias de família, com avós ou antigos moradores, sobre o bairro e sua formação.

Esses dados podem ser encarados como informações estáticas, registros apenas do que aconteceu no passado. No entanto, ao focalizar os dados do ponto de vista da Toponímia, as denominações se tornam signos a serem decifrados em toda a sua complexa extensão na busca de seus sentidos e de sua motivação. Assim, o ensino de História, de Geografia, de Artes, de Língua Portuguesa pode ter como ponto de partida a realidade do bairro. 
Portanto, para os membros de uma comunidade, além de referir um objeto, o nome de um lugar conota traços culturais que são caros a essa comunidade. Ou, expressando de outra maneira, um topônimo carrega consigo a sua possibilidade de descrição e esta está impregnada de traços culturais que perpassam a vida de todas as pessoas que constituem esse específico grupo social. Mais ainda se elas participam de sua criação. (FROSI; FAGGION; DAL CORNO, 2008, p. 3020)

\section{Toponímia na escola: o mesmo bairro, mas um enfoque diferente}

Os estudos em Toponímia no Brasil vêm se intensificando desde o final do século XX, oferecendo à comunidade acadêmicocientífica subsídios para uma melhor compreensão de aspectos históricos, geográficos e culturais dos lugares que eles denominam. À medida que a academia compreende a importância do estudo dos topônimos, compreende também seu valor como uma ferramenta auxiliar no ensino desses aspectos desde a educação básica.

Para Melo,

[...] a inclusão dos estudos toponímicos no currículo escolar, entre os assuntos tratados nas aulas de Língua Portuguesa, permite a aplicação da referida orientação [dada nos PCNs], já que essa disciplina onomástica caracteriza-se, exatamente, pela interdisciplinaridade inerente, e necessária, para a análise e compreensão do sentido que o topônimo possui. O trabalho com a toponímia articulará saberes geográficos, históricos, biológicos, antropológicos, além, é claro, de saberes lingüísticos. (MELO, 2007, p. 4)

Melo (2007) faz uma proposta bem elaborada para a inclusão formal dos estudos toponímicos na escola. Esse tipo de proposta contribui sobremaneira para o levantamento e registro de dados dessa natureza, sendo por isso muito útil quando esse registro é inexistente. Uma desvantagem, porém, precisa ser apontada: é necessário que o professor tenha uma formação adequada para conduzir com eficácia as atividades ali propostas. 
Também se observam iniciativas que revelam uma preocupação com a valorização de pontos ou roteiros turísticos. Um exemplo é o jogo recentemente lançado pelas alunas do curso de Turismo da Faculdade Cenecista, Josirene de Mattos Pinto, Quéli Lopes Choquetta e Suélen Matias da Silva, sob orientação de Cristina Schneider, divulgado no Jornal Semanário de Bento Gonçalves, em reportagem de Luiz Inácio. O objetivo foi o de dar aos participantes a oportunidade de conhecer melhor o roteiro turístico Caminhos de Pedra.

A proposta que ora apresentamos é, de certo modo, mais singela que as mencionadas acima, visando muito mais a despertar a curiosidade dos alunos de modo a treinar-lhes o olhar para as informações toponímicas com as quais se deparam no dia-a-dia, muitas vezes sem prestar-lhes atenção. As atividades podem ser conduzidas de forma interdisciplinar. Se aplicadas entre o quarto e o quinto anos, o professor titular pode encarregar-se delas, contando com o auxílio da Educação Física (geralmente ministrada por outro docente) para as saídas a campo; se aplicadas do sexto ano em diante, os professores de diversas disciplinas podem ficar responsáveis pela aplicação e avaliação das atividades. A proposta está esquematizada como segue.

\section{Uma proposta de atividades para o ensino dos topônimos na escola}

l Objetivo Geral

Oportunizar aos alunos, através do topônimo "bairro Nossa Senhora de Lourdes", conhecimentos básicos a respeito do bairro, despertando sua curiosidade e treinando seu olhar para a percepção da cultura subjacente aos hodônimos identificados.

2 Objetivos Específicos

Propiciar situações de aprendizagem que contribuam a levar o aluno a: 

pais ruas;

a) conhecer a história cultural do bairro e das suas princi-

b) estabelecer relações entre o topônimo bairro Nossa Senhora de Lourdes, bem como seus hodônimos, e essa história;

c) reconhecer os principais pontos turísticos do bairro;

d) valorizar o conhecimento de vida de familiares e moradores mais antigos do bairro;

e) valorizar o trabalho em equipe e a integração entre as turmas.

\section{Público-alvo}

Alunos a partir do terceiro ano do Ensino Fundamental, podendo envolver os alunos dos anos finais.

\section{Duração}

Um a dois meses, com atividades diluídas em uma ou mais disciplinas, por pelo menos uma hora semanal.

5 Sequência de atividades

A primeira atividade sugerida é uma conversa, bate-papo ou palestra (dependendo do nível das turmas) sobre o bairro Nossa Senhora de Lourdes, abrangendo o histórico do bairro, a evolução do nome, os pontos turísticos, as ruas principais;

Ao final da palestra ou bate-papo, são lançadas as tarefas para uma Gincana Cultural, a serem desenvolvidas pelas turmas durante um período pré-determinado, com prazos estabelecidos para resolução. Como acontece geralmente em gincanas, pode ser pensado um prêmio a ser entregue à equipe (turma) que tiver melhor desempenho ao final. Diferentemente das gincanas tradicionais, porém, as respostas às questões das tarefas devem ser divulgadas e aproveitadas como motivação para as aulas (cada disciplina aproveitando o aspecto que melhor lhe aprouver, conforme sugestôes adiante).

Sugerimos três tipos de tarefas motivadoras, "Que lugar é este?", "Você reconhece?" e "Charadas sobre os lugares e seus hodônimos”, descritas a seguir. 


\section{Primeira tarefa: Que lugar é esse?}

Através de fotografias antigas de edificações e estabelecimentos comerciais, os alunos devem descobrir:

- que lugar está sendo retratado;

- $\quad$ sua localização;

- se atualmente abriga o mesmo estabelecimento mostrado na fotografia, ou se serve ainda às mesmas funções.

Fotografias antigas podem ser obtidas junto ao Arquivo Histórico, mediante autorização para divulgação. Exemplos de lugares que podem ser retratados: antigo Hospital Carbone, atual Arquivo Histórico; capela do Santo Sepulcro (diferentes épocas); Monumento ao Imigrante (por exemplo, em construção); Igreja Nossa Senhora de Lourdes (em construção); antiga fábrica de máquinas Favaro (Fig. 1), atual estabelecimento comercial (Fig. 2 ); casas antigas do bairro, etc. Todas as fotos devem ser disponibilizadas em um pôster, que ficaria exposto na escola, podendo também ser feitas cópias em tamanho reduzido para cada sala de aula envolvida na atividade. Os alunos provavelmente precisarão recorrer a pessoas mais idosas, familiares ou antigos moradores do bairro, para recuperar alguns detalhes da história.

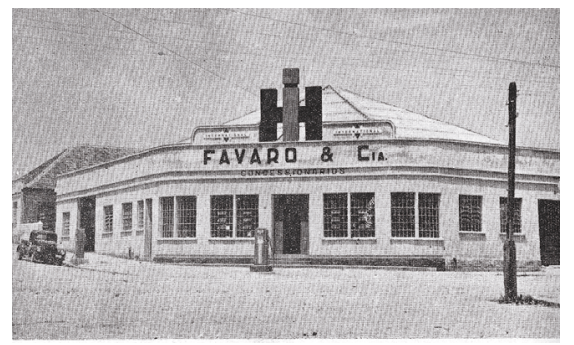

Fig. 1: Prédio da antiga fábrica de máquinas de Favaro \& Cia. (Fonte: Álbum Comemorativo do $75^{\circ}$ Aniversário da Colonização Italiana no Rio Grande do Sul) 


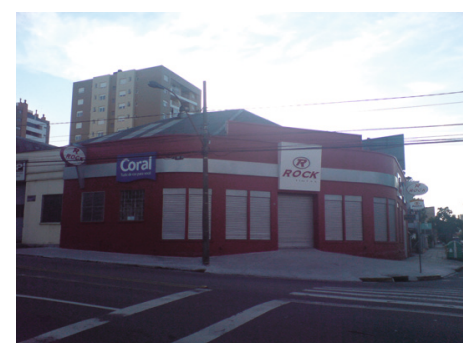

Fig. 2: Fachada atual do prédio, hoje um estabelecimento comercial (Crédito da fotografia: as autoras)

Como sequência, podem ser realizadas atividades de: localização dos lugares estudados em cartas geográficas da cidade, pesquisa em imagens de satélite (ex.: Google Earth), identificação de coordenadas (Geografia); relação com fatos e acontecimentos históricos (História).

\section{Segunda tarefa: Você reconhece?}

Por meio de fotos de detalhes de alguns lugares, como edificações ou monumentos importantes do bairro, os alunos devem:

- decifrar qual é o lugar retratado; e

- indicar sua localização.

Exemplos de detalhes que podem ser fotografados: globo sobre a antiga cantina Michielon (Fig. 3); placa no Arquivo Histórico com o antigo nome da rua Gauchinha (Fig. 4); abóbada da Capela do Santo Sepulcro (Fig. 5); escadaria da avenida Júlio de Castilhos; detalhes da praça Vestibular Getúlio Vargas e de outros lugares mencionados acima. Todas as fotos devem ser disponibilizadas em um pôster que ficaria exposto na escola, podendo também ser feitas cópias em tamanho reduzido para cada sala de aula envolvida na atividade.

As turmas podem ser organizadas para um passeio pelo bairro, buscando localizar e identificar esses detalhes (como nas aulas de Educação Física), ou a tarefa pode ser lançada como algo a ser realizado com a família (no caso das crianças mais 
jovens) ou em grupos de colegas no turno contrário ao da aula ou durante os finais de semana.

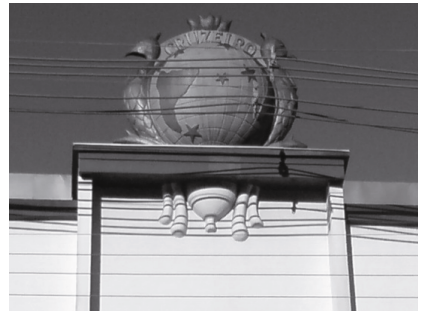

Fig. 3: Globo sobre a antiga Cantina Michielon

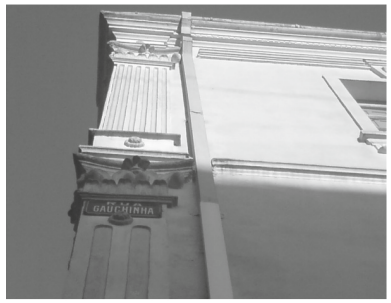

Fig. 4: Placa indicando "Rua Gauchinha" na fachada do Arquivo Histórico Municipal

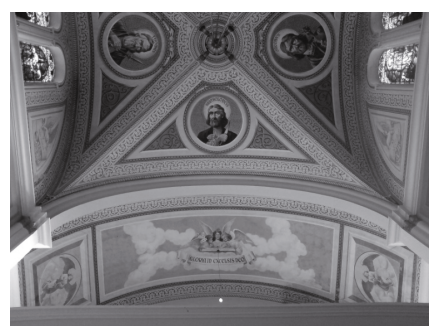

Fig. 5: Detalhe da abóbada da Capela do Santo Sepulcro (Crédito das fotografias: as autoras)

Como sequência, novamente pode ser feita a identificação da localização nas cartas geográficas (Geografia). Além disso, podem ser investigados os nomes das ruas, buscando classificá-los segundo a tipologia proposta por Dick (1990) e outros (Língua Portuguesa). Mais importante ainda, ao se deparar com a grande quantidade de antropo-hodônimos, o professor poderia 
sugerir à turma a investigação das pessoas homenageadas nessas denominaçôes. Novamente, pode haver necessidade de recorrer a pessoas mais velhas, e às vezes os alunos poderão se surpreender com o fato de que os familiares ou vizinhos conheceram alguns dos homenageados (parte da História). Os detalhes podem ser um material riquíssimo para o estudo de estilos arquitetônicos e tendências (Educação Artística).

\section{Terceira tarefa: Charadas sobre lugares e seus hodônimos}

Para enfatizar o aspecto lúdico das atividades, seriam lançadas algumas charadas a serem decifradas pelos alunos. Novamente, pode ser necessário o auxílio da família ou de moradores mais antigos do bairro. Exemplos:

- Já fui armazém, depois hospital, agora guardo

a memória municipal.

Quem sou?

(Resposta: Arquivo Histórico Municipal João Spadari Adami)

- Guerreiro lutador

que vence o inimigo

sua tribo é do bairro

um nome muito antigo.

Quem sou?

(Resposta: Guarani)

Como sequência, os próprios alunos poderiam criar charadas para propor aos colegas ou às outras turmas, envolvendo seu conhecimento dos lugares, dos hodônimos que os denominam e também sua habilidade de produção textual. 


\section{Para finalizar}

Os nomes dos lugares não são meros marcos referenciais: eles revelam muito da história sociocultural de determinado grupo. Dito de outra maneira:

Os topônimos são sinais importantes, indicativos da cultura, da história e da linguagem de um povo. Ditos ou escritos, os topônimos propiciam informações a respeito das sucessivas gerações de uma localidade, dos homens que aí nasceram, trabalharam e viveram, bem como daqueles que mereceram sua homenagem. Aludem a fatos e datas significativas, dão conta das devoções, traduzem sentimentos. Assim, saber o exato significado do nome de uma cidade, bem como de suas ruas, praças e parques, significa verdadeiramente conhecer essa cidade e reconhecer os seus valores. (FAGGION; DAL CORNO; FROSI, 2008, p. 278)

As propostas que aqui apresentamos podem servir como base para desenvolvimento de outras, aplicáveis a cidades ou bairros específicos. Acreditamos que as atividades envolvendo aspectos da Toponímia e o estudo dos topônimos como fatos da linguagem possam motivar o trabalho com diversas disciplinas na escola, auxiliando, deste modo, os alunos/cidadãos a "conhecer e valorizar a pluralidade do patrimônio sociocultural brasileiro." (PCNs, 1998, p. 07).

Que tal experimentar?

\section{Referências}

BERTASO, Henrique D'Ávila; LIMA, Mario de Almeida (Orgs.). Álbum comemorativo do $75^{\circ}$ aniversário da colonização italiana no Rio Grande do Sul. Porto Alegre: Revista do Globo, 1950.

BRASIL. Secretaria de Educação Fundamental. Parâmetros Curriculares Nacionais $3^{\circ}$ e $4^{\circ}$ ciclos do Ensino Fundamental - Língua Portuguesa. Brasília: MEC/SEF, 1998.

CARVALHINHOS, Patrícia de Jesus. Estudos de onomástica em língua portuguesa no Brasil: perspectivas para inserção mundial. Anais do 
I SIMELP - Simpósio Mundial de Estudos de Língua Portuguesa. São Paulo: USP; UNICSUL, 2008.

COSTA, Ana Elísia da; MACHADO, Maria Beatriz P.; VENZO, Michele. Toigo: architecto - constructor licenciado. Métis: história e cultura. Caxias do Sul, Educs, v. 7, n. 13, p. 169-191, jan./jun. 2008.

DICK, Maria Vicentina de P. do A. Toponímia e antroponímia no Brasil: coletânea de estudos. 2 ed. São Paulo: FLCH;USP, 1990.

FAGGION, Carmem M.; DAL CORNO, Giselle O. M.; FROSI, Vitalina M. Topônimos em Bento Gonçalves: motivação e caracterização. Métis: história e cultura. Caxias do Sul: Educs, v. 7, n. 13, p. 277-298, jan./jun. 2008.

FROSI, Vitalina M. Os hodônimos de uma praça: suas interfaces, seus significados. In: DA HORA, Dermeval (Org.). VI Congresso Internacional da ABRAlin. Anais... João Pessoa: Ideia, p. 3024-3030, 2009. 1 CDRom.

FROSI, Vitalina M. Nomes italianos para estradas brasileiras. In: MARÇALO, Maria João; LIMA-HERNANDES, Maria Célia; ESTEVES, Elisa; FONSECA, Maria do Céu; GONÇALVES, Olga; VILELA, Ana Luísa; SILVA, Ana Alexandra (Eds.). Língua portuguesa: ultrapassar fronteiras, juntar culturas. Évora: Universidade de Évora, 2010. p. 50-73. Disponível em http://www.simelp2009.uevora.pt;slgs;slg23.htm. Acesso em 10 de nov. 2010.

FROSI, Vitalina M.; DAL CORNO, Giselle O. M.; FAGGION. Carmen M. Topônimos na RCI: resgate da identidade cultural. In: MAGALHÃES, José Sueli de; TRAVAGLIA, Luiz Carlos (Orgs.). Múltiplas perspectivas em lingüistica. Uberlândia: EDUFU, p. 3017-3029, 2008. 1 CD-Rom.

GIRON, Loraine Slomp; BERGAMASCHI, Heloísa E. Casas de negócio: 125 anos de imigração italiana e o comércio regional. Caxias do Sul: Educs, 2001.

IGREJA DO SANTO SEPULCRO. Disponível em: http://tetraktys. multiply.com/photos/album/210. Acesso em 14 de nov. 2010.

INÁCIO, Luiz. Pela história dos Caminhos de Pedra. Jornal Semanário. Bento Gonçalves, sábado, 20 de novembro de 2010, p. 23. 
MACHADO, Maria Abel. Construindo uma cidade: história de Caxias do Sul 1875/1950. Caxias do Sul: Maneco, 2001

MONUMENTO NACIONAL AO IMIGRANTE. Disponível em http:// pt.wikipedia.org/wiki/Monumento_Nacional_ao_Imigrante. Acesso em 14 de nov. 2010.

OLIVEIRA, Ana Maria P. P.; ISQUERDO, Aparecida Negri (Orgs.). As ciências do léxico: lexicologia, lexicografia, terminologia. 2 ed. Campo Grande: UFMS, 2001.

PREFEITURA MUNICIPAL DE CAXIAS DO SUL. Banco de Memória do Arquivo Histórico Municipal João Spadari Adami.

SANTOS, Elisa Jaques dos; DAL CORNO, Giselle Olivia Mantovani. Toponímia na escola: uma proposta interdisciplinar. XVIII Encontro de Jovens Pesquisadores: resumos dos trabalhos. Universidade de Caxias do Sul, setembro de 2010. Disponível em http://www.ucs.br/ucs/pesquisa/ jovenspesquisadores2010/capa/encontro. Acesso em 10 de nov. 2010.

SANTOS, Elisa Jaques dos; DAL CORNO, Giselle Olivia Mantovani; FROSI, Vitalina M.; FAGGION, Carmen M. De caipora a Nossa Senhora deLourdes: a evolução de um topônimo no município de Caxias do Sul.XVII Encontro de Jovens Pesquisadores: resumos dos trabalhos. Universidade de Caxias do Sul, setembro de 2009. Disponível em http://www.ucs.br/ ucs/tplJovensPesquisadores2009/pesquisa/jovenspesquisadores2009/ trabalhos/resumo/humanas/ElisaJaquesdosSantos.pdf. Acesso em 10 de nov. 2010.

SOUSA, Alexandre Melo. Aplicação dos estudos toponímicos no Ensino Fundamental e Médio: propostas teórico-didáticas. Recanto das Letras, dezembro 2007. Disponível em http://recantodasletras.uol.com.br/ artigos/764150. Acesso em 16 de jun. 2009. 